\title{
Predictive Factors for Delivery within 7 Days after Successful 48-Hour Treatment of Threatened Preterm Labor
}

\author{
Carolien Roos, MD, PhD ${ }^{1}$ Ewoud Schuit, MSc, PhD ${ }^{2}$ Hubertina C. J. Scheepers, MD, PhD ${ }^{3}$
} Kitty W. M. Bloemenkamp, MD, $\mathrm{PhD}^{4}$ Antoinette C. Bolte, MD, $\mathrm{PhD}^{1}$ Hans J. J. Duvekot, MD, $\mathrm{PhD}^{5}$ Jim van Eyck, MD, $\mathrm{PhD}^{6}$ Joke H. Kok, MD, $\mathrm{PhD}^{7}$ Anneke Kwee, MD, $\mathrm{PhD}^{8}$ Ashley E. R. Merién, $\mathrm{MD}^{9}$ Brent C. Opmeer, $\mathrm{PhD}^{10}$ Martijn A. Oudijk, MD, $\mathrm{PhD}^{8}$ Mariëlle G. van Pampus, MD, PhD ${ }^{11}$ Dimitri N. M. Papatsonis, MD, PhD ${ }^{12}$ Martina M. Porath, MD, PhD ${ }^{13}$ Krystyna M. Sollie, MD, PhD ${ }^{14}$ Marc E. A. Spaanderman, MD, PhD ${ }^{3}$ Sylvia M. C. Vijgen, MSc, PhD ${ }^{15}$ Christine Willekes, MD, PhD Fred K. Lotgering, MD, PhD ${ }^{1}$ Joris A. M. van der Post, MD, $\mathrm{PhD}^{16}$ Ben Willem J. Mol, MD, PhD ${ }^{17}$ for APOSTEL-II Study Group

\footnotetext{
1 Department of Obstetrics and Gynecology, Radboud University Medical Center, Nijmegen, The Netherlands

2 Julius Center for Health Sciences and Primary Care, University Medical Center Utrecht, Utrecht, The Netherlands

${ }^{3}$ Department of Obstetrics and Gynecology, Maastricht University Medical Center, GROW School for Oncology and Developmental Biology, Maastricht, The Netherlands

${ }^{4}$ Department of Obstetrics and Gynecology, Leiden University Medical Center, Leiden, The Netherlands

${ }^{5}$ Department of Obstetrics and Gynecology, Erasmus Medical Center, Rotterdam, The Netherlands

6 Department of Obstetrics and Gynecology, Isala Clinics, Zwolle, The Netherlands

${ }^{7}$ Department of Neonatology, Academic Medical Center, Amsterdam, The Netherlands

8 Department of Obstetrics and Gynecology, University Medical Center Utrecht, Utrecht, The Netherlands

${ }^{9}$ Department of Obstetrics and Gynecology, Ziekenhuis Rijnstate, Arnhem, The Netherlands

${ }^{10}$ Clinical Research Unit, Academic Medical Center, Amsterdam, The Netherlands

${ }^{11}$ Department of Obstetrics and Gynecology, Onze Lieve Vrouwe Gasthuis, Amsterdam, The Netherlands

12 Department of Obstetrics and Gynecology, Amphia Hospital, Breda, The Netherlands

13 Department of Obstetrics and Gynecology, Máxima Medical Center, Veldhoven, The Netherlands

${ }^{14}$ Department of Obstetrics and Gynecology, University Medical Center, Groningen, The Netherlands

${ }^{15}$ College voor Zorgverzekeringen, Diemen, The Netherlands

16 Department of Obstetrics and Gynecology, Academic Medical Center, Amsterdam, The Netherlands

${ }^{17}$ The Robinson Institute, School of Paediatrics and Reproductive Health, University of Adelaide, Adelaide, Australia
}

Am J Perinatol Rep 2015;5:e141-e149.
Address for correspondence Carolien Roos, MD, PhD, Department of Obstetrics and Gynecology, Radboud University Medical Center, Huispostnummer 791, Postbus 9101, 6500 HB, Nijmegen, The Netherlands (e-mail: carolienroos1@gmail.com). received

November 23, 2014 accepted after revision March 25, 2015 published online June 3, 2015
DOI http://dx.doi.org/ 10.1055/s-0035-1552930. ISSN 2157-7005.
Copyright $\odot 2015$ by Thieme Medical Publishers, Inc., 333 Seventh Avenue, New York, NY 10001, USA. Tel: +1(212) 584-4662.
License terms

(c) (1) $\ominus$ (\$) 


\begin{abstract}

\section{Keywords}

- predictive factors

- preterm delivery

- maintenance tocolysis

Objective The aim of this study was to assess which characteristics and results of vaginal examination are predictive for delivery within 7 days, in women with threatened preterm labor after initial treatment.

Study Design A secondary analysis of a randomized controlled trial on maintenance nifedipine includes women who remained undelivered after threatened preterm labor for 48 hours. We developed one model for women with premature prelabor rupture of membranes (PPROM) and one without PPROM. The predictors were identified by backward selection. We assessed calibration and discrimination and used bootstrapping techniques to correct for potential overfitting.

Results For women with PPROM (model 1), nulliparity, history of preterm birth, and vaginal bleeding were included in the multivariable analysis. For women without PPROM (model 2), maternal age, vaginal bleeding, cervical length, and fetal fibronectin (fFN) status were in the multivariable analysis. Discriminative capability was moderate to good (c-statistic $0.68 ; 95 \%$ confidence interval [CI] 0.60-0.77 for model 1 and $0.89 ; 95 \%$ $\mathrm{Cl}, 0.84-0.93$ for model 2).

Conclusion PPROM and vaginal bleeding in the current pregnancy are relevant predictive factors in all women, as are maternal age, cervical length, and fFN in women without PPROM and nulliparity, history of preterm birth in women with PPROM.
\end{abstract}

Preterm birth accounts for half of the childhood neurodevelopmental disabilities and almost $75 \%$ of perinatal deaths occur in infants born before 37 weeks' gestation. ${ }^{1,2}$ Although approximately $75 \%$ of women presenting with threatened preterm labor remain initially undelivered after an initial course of tocolytics of 48 hours, their risk of preterm delivery after this period is still increased; $65 \%$ of women deliver before 37 weeks. ${ }^{3}$ Unfortunately, the risk is difficult to estimate for the individual woman. Previously, several factors such as short cervical length and positive fetal fibronectin (fFN) have been shown to be predictors of early delivery in pregnant women. ${ }^{4,5}$ It is important to identify women who will deliver within 1 week because women with a high risk may benefit from prolonged hospitalization in a tertiary center $^{6}$ and other management options for preterm labor. Since preterm birth is multifactorial, ${ }^{7}$ it is likely that a single test alone cannot predict preterm birth accurately.

In the present study, we assessed which demographic and clinical characteristics, results of vaginal examination and laboratory variables are predictive factors for delivery within 7 days in women with threatened preterm labor who had not delivered within 48 hours after initial treatment.

\section{Materials and Methods}

\section{Setting}

This is a secondary analysis of the APOSTEL-II trial (Assessment of Perinatal Outcome with Sustained Tocolysis in Early Labor), performed between June 2008 and February 2010. Women with threatened preterm labor between $26^{+0}$ and $32^{+2}$ weeks gestational age were randomly allocated to maintenance tocolysis with nifedipine or placebo. At that point, women had already been treated with tocolytics for 48 hours to complete a course of corticosteroids. Both the randomized controlled trial and the secondary analysis were approved by the Institutional Review Board of the participating hospitals. The design and main results have been previously published. ${ }^{8,9}$ All participants gave informed consent. Because the trial has shown that maintenance therapy is ineffective in prolonging pregnancy and improving perinatal outcome, both women with maintenance tocolytic therapy and women with placebo were included in the analysis. Also women refusing randomization, but consenting follow-up of their data (the nonrandomized group) were included in the present study. Data were entered in a database by research nurses and midwives and validation of the data was performed by the lead author of this article.

\section{Outcome}

The outcome variable of primary interest of our prediction models was delivery within 7 days after initial 48 hours of arrest of preterm labor.

\section{Predictors under Study}

Based on the literature ${ }^{10-13}$ and expert experience, we identified candidate predictors for delivery within 7 days after arrest of threatened preterm labor. Candidate predictors were maternal age, ethnicity, education level, body mass index, history of preterm birth before 32 weeks and before 37 weeks, multifetal gestation, premature prelabor rupture of membranes (PPROM), vaginal bleeding at study entry, Group B Streptococcus status, C-reactive protein (CRP) at study entry, fFN at study entry, dilatation at study entry (digital exam), and cervical length at study entry (ultrasound). A combination of parity and a history of preterm birth were categorized into multiparous women with a prior birth $\geq 37$ weeks' gestation (reference), nulliparous women, multiparous women with a prior birth $<32$ weeks, and multiparous women with a prior birth 32 to 37 weeks. We developed two separate models, one for women with PPROM (model 1) in whom the 
variables dilatation, cervical length, and fFN had not been assessed, and one for women without PPROM (model 2) which included these variables.

\section{Data Analysis}

Associations between the candidate predictors and delivery within 7 days were analyzed with logistic regression analysis. Although generally not recommended, ${ }^{14}$ we performed a preselection based on the univariable analyses $p$-value $(<0.20)$ to retain a reasonable number of events per variable in the multivariable model. ${ }^{15}$

Maternal age, body mass index, gestational age, CRP, dilatation, and cervical length were analyzed as continuous variables. Linearity of their association with the outcome was assessed using cubic spline analyses. ${ }^{16}$ In case of no linearity, variables were transformed with logistic transformation or the addition of a quadratic term according to the shape of their plots. All other variables were dichotomous. To correct for the allocated intervention in the original trial, we also included intervention as a variable in the analysis.

Various subjects had missing values, ranging from $0 \%$ missing values in maternal age to $60 \%$ in fFN in women without PPROM. Because missing values could be selectively missing, complete case analysis may yield to biased results. ${ }^{17-19}$ Hence, before performing the analyses, the missing values were imputed using multiple imputation (10 times). The imputation model included all potential predictors as well as the outcome of interest. ${ }^{16,20-22}$

In prognostic model research, there is a chance of finding spurious predictors and overestimated regression coefficients. $^{16,20,23}$ Such overfitted models will create too extreme and optimistic predictions when applied in new cohorts. To assess the degree of overfitting or optimism in this study, we (internally) validated the models using bootstrapping techniques. ${ }^{24}$ This yielded a shrinkage factor, with which the regression coefficients were multiplied (uniformly shrunken) to adjust for overfitting and optimism. All analyses including the bootstrapping techniques were performed in $R$ version 2.10 .0 (The $R$ Foundation for Statistical Computing, 2009, Vienna, Austria).
The ability of the two models to discriminate between women who delivered within or beyond 7 days was quantified with the area under the receiver operating characteristic curve ( $c$-statistic). Calibration was assessed by comparing the predicted probabilities with the observed frequencies of delivery within 7 days. The agreement between the observed proportions of delivery within 7 days and the predicted risks was studied with calibration plots, ${ }^{16,25}$ which provided additional insight in the distribution of the predicted outcome incidences.

\section{Results}

In the APOSTEL-II trial, 636 women were eligible for participation, of whom 406 women gave informed consent for randomization between maintenance tocolysis with nifedipine (201 women) and placebo (205 women) (-Fig. 1). The other 230 women refused randomization but gave informed consent for follow-up of their medical data. There was no loss to follow-up in the randomization group, while eight women were lost to follow-up in the nonrandomization group.

Baseline characteristics for the total cohort of 628 women for complete cases $(n=30)$ and for cases with one or more missing variable $(n=598)$ are shown in Appendix 1. Values after imputation are displayed in - Table 1. Delivery within 1 week after arrest of threatened preterm labor occurred in 151 women (24\%), 61 of 144 (42\%) women with PPROM and 90 of 484 (19\%) women without PPROM $(p<0.001)$. This indicates that PPROM is a major predictive factor for delivery within 7 days. Some variables were not linear with the outcome. For women without PPROM, maternal age and CRP were transformed with logistic transformation.

- Table 2 summarizes the baseline characteristics of the women who had PPROM at inclusion for women who delivered within 1 week versus those who delivered beyond that week. The results of the univariable and multivariable analyses for all women with PPROM are shown in the same table. In the univariable analysis, variables related to delivery within 7 days in women with PPROM were nulliparity (odds ratio

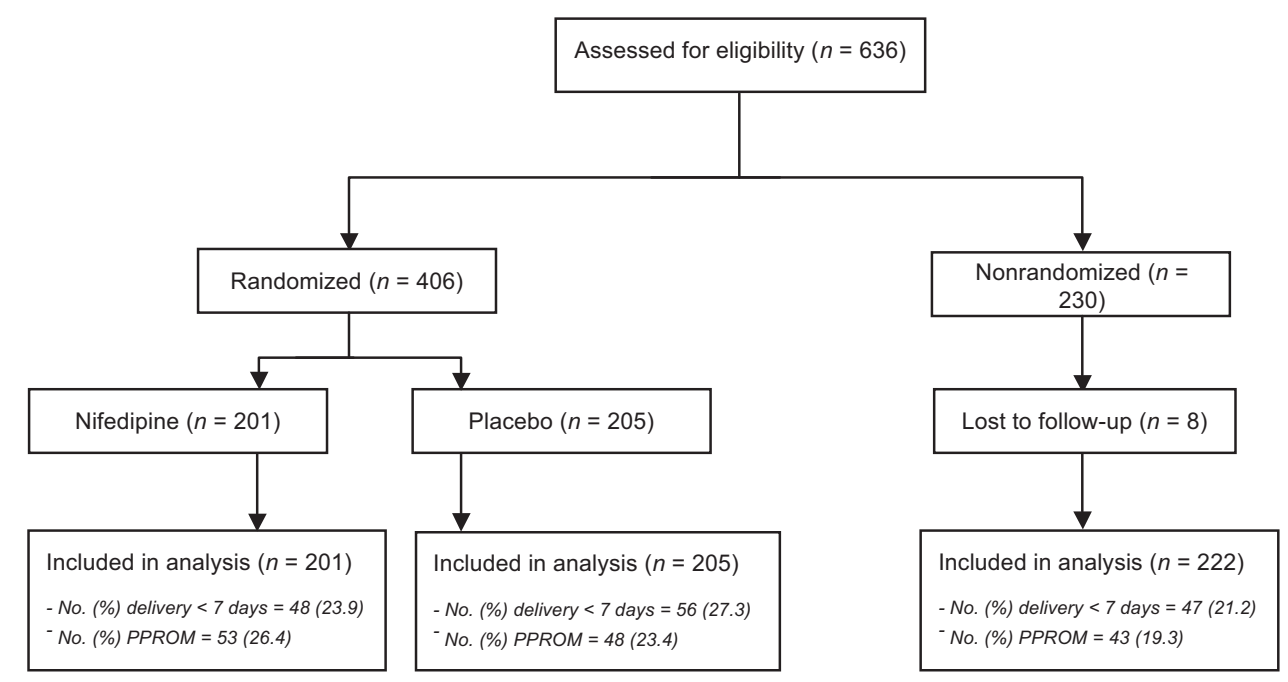

Fig. 1 Trial profile of the APOSTEL-II trial (Assessment of Perinatal Outcome with Sustained Tocolysis in Early Labor). 
Table 1 Baseline demographics and clinical characteristics for the total study cohort

\begin{tabular}{|c|c|}
\hline Total study population $(n=628)$ & Value after imputation \\
\hline Age $(y)^{a}$ & $29.7 \pm 5.3$ \\
\hline Non-Caucasian ethnicity & $117(19)$ \\
\hline Low educational level $^{\mathrm{b}}$ & $368(59)$ \\
\hline \multicolumn{2}{|l|}{ Parity and prior preterm birth } \\
\hline Prior birth $\geq 37 \mathrm{wk}$ & $146(23)$ \\
\hline Nulliparous & $353(56)$ \\
\hline Prior preterm birth $<32 \mathrm{wk}$ & $74(12)$ \\
\hline Prior preterm birth 32-37 wk & $55(9)$ \\
\hline Body mass index ${ }^{c}$ & $22.5(20.4-26.4)$ \\
\hline Multifetal gestation & $135(21)$ \\
\hline PPROM & $144(23)$ \\
\hline Vaginal bleeding & $118(19)$ \\
\hline \multicolumn{2}{|l|}{ Laboratory examination at study entry } \\
\hline C-reactive protein $(\mathrm{g} / \mathrm{L})$ & $8(3-24)$ \\
\hline Streptococcus Group B positive & $139(22)$ \\
\hline Fibronectin status positive & $189(30)$ \\
\hline \multicolumn{2}{|l|}{ Vaginal examination at study entry } \\
\hline Dilatation at study entry & $1(0-2)$ \\
\hline Cervical length at study entry, $\mathrm{mm}$ & $23(15-31)$ \\
\hline \multicolumn{2}{|l|}{ Randomized } \\
\hline No & $222(35)$ \\
\hline Yes, placebo & $205(33)$ \\
\hline Yes, nifedipine & $201(32)$ \\
\hline Delivery $<7 \mathrm{~d}$ & $151(24)$ \\
\hline
\end{tabular}

Abbreviation: PPROM, premature prelabor rupture of membranes.

${ }^{a}$ Data are mean \pm standard deviation, median (interquartile range) or number $(\%)$.

bLow educational level is defined as primary, secondary, or lower professional school as highest finished education.

${ }^{\mathrm{c}}$ The body mass index is weight $(\mathrm{kg})$ divided by square height $\left(\mathrm{m}^{2}\right)$.

[OR], 3.6; 95\% confidence interval [CI], 1.6-8.5) and prior preterm birth 32 to 37 weeks (OR, 3.5; $95 \% \mathrm{CI}, 1.0-12$ as compared with a prior birth $\geq 37$ weeks). After backward selection, nulliparity, prior preterm birth $<32$ and 32 to 37 weeks, and vaginal bleeding were included in the model.

- Table 3 shows the baseline characteristics of the women without PPROM at inclusion, also divided in women who delivered within 1 week and women who delivered beyond 1 week. In the univariable analysis, variables related to delivery within 1 week were vaginal bleeding (OR, 4.6; 95\% CI, 2.8-7.8), positive fFN status (OR, 14.97; 95\% CI, 5.1-44), dilatation (OR, 1.9; 95\% CI, 1.5-2.4), cervical length (OR, 0.4; $95 \% \mathrm{CI}, 0.3-0.5$ ), and placebo study medication (OR, 2.0; $95 \%$ CI, 1.1-3.5). After backward selection, maternal age, vaginal bleeding, positive fFN status, and cervical length were included in the model. Both multivariable models showed moderate to good discriminative ability, with c-statistics of $0.68(95 \% \mathrm{Cl}$, $0.60-0.77$ ) for the model with PPROM and 0.89 (95\% CI, 0.84 0.93 ) for the model without PPROM. Calibration plots of both models are shown in - Fig. $\mathbf{2 a}$, $\mathbf{b}$ and show good agreement between predicted risk and observed proportions, which indicates good calibration.

\section{Discussion}

In this study, we investigated if women at increased risk of delivery within 7 days after arrest of threatened preterm labor could be identified from certain antepartum characteristics. Our results from the multivariable analysis show that in women with PPROM, the relevant predictive variables are nulliparity, previous preterm delivery $<32$ and 32 to 37 weeks' gestation, and vaginal bleeding. In women without PPROM, predictive variables were maternal age, vaginal bleeding, positive fFN status, and cervical length. The analytic models show moderate discriminative capability for women with PPROM and good discriminative capability for women without PPROM.

Using the multivariable associations, it is possible to calculate the risk of delivery within 7 days after arrest of threatened preterm labor, the next formula can be used: 
Table 2 Univariable and multivariable analyses for the prediction of delivery within 7 days after successful 48 hours treatment of threatened preterm labor in women with PPROM

\begin{tabular}{|c|c|c|c|c|c|c|}
\hline \multirow{2}{*}{$\begin{array}{l}\text { Women with PPROM } \\
(n=144,23 \%)\end{array}$} & \multirow[t]{2}{*}{ Delivery $<7 \mathrm{~d}$} & \multirow[t]{2}{*}{ Delivery $>7 \mathrm{~d}$} & \multicolumn{2}{|c|}{ Univariable analysis } & \multicolumn{2}{|c|}{ Multivariable analysis } \\
\hline & & & $\begin{array}{l}\text { Odds ratio } \\
(95 \% \mathrm{Cl})^{\mathrm{a}}\end{array}$ & $p$-Value & $\begin{array}{l}\text { Beta } \\
\text { coefficient }\end{array}$ & $\begin{array}{l}\text { Odds ratio } \\
(95 \% \mathrm{Cl})\end{array}$ \\
\hline Characteristic & $n=61(43 \%)$ & $n=83(58 \%)$ & & & & \\
\hline Age $(y)^{b}$ & $31.4 \pm 5.4$ & $30.4 \pm 4.7$ & $1.04(0.98-1.12)$ & 0.21 & & \\
\hline $\begin{array}{l}\text { Non-Caucasian } \\
\text { ethnicity }\end{array}$ & $13(21)$ & $21(25)$ & $0.80(0.35-1.81)$ & 0.59 & & \\
\hline Low educational level & $34(56)$ & $52(63)$ & $0.75(0.31-1.83)$ & 0.53 & & \\
\hline \multicolumn{7}{|c|}{ Parity and prior preterm birth } \\
\hline Prior birth $\geq 37$ wk & $10(16)$ & $31(37)$ & Reference & & & \\
\hline Nulliparous & $41(66)$ & $35(42)$ & $3.63(1.56-8.47)$ & 0.003 & 1.02 & $2.77(1.15-6.65)$ \\
\hline $\begin{array}{l}\text { Prior preterm } \\
\text { birth }<32 \mathrm{wk}\end{array}$ & $3(5)$ & $10(12)$ & $0.93(0.21-4.06)$ & 0.92 & -0.015 & $0.99(0.22-4.39)$ \\
\hline $\begin{array}{l}\text { Prior preterm } \\
\text { birth } 32-37 \text { wk }\end{array}$ & $8(13)$ & $7(8)$ & $3.54(1.03-12.2)$ & 0.046 & 0.99 & $2.70(0.76-9.58)$ \\
\hline $\begin{array}{l}\text { Body mass index } \\
\left(\mathrm{kg} / \mathrm{m}^{2}\right)\end{array}$ & $22.8(20.5-25.3)$ & $24.0(20.5-28.6)$ & $0.96(0.89-1.03)$ & 0.53 & & \\
\hline Multifetal gestation & $14(23)$ & $14(17)$ & $1.49(0.65-3.42)$ & 0.34 & & \\
\hline Vaginal bleeding & $17(28)$ & $15(18)$ & $1.73(0.78-3.82)$ & 0.18 & 0.57 & $1.77(0.75-4.17)$ \\
\hline C-reactive protein $(\mathrm{g} / \mathrm{L})$ & $10(3-31)$ & $9(3-30)$ & $1.00(0.99-1.02)$ & 0.77 & & \\
\hline $\begin{array}{l}\text { Streptococcus Group } \\
\text { B positive }\end{array}$ & $15(24)$ & $20(24)$ & $0.98(0.34-2.83)$ & 0.97 & & \\
\hline \multicolumn{7}{|l|}{ Randomized } \\
\hline No & $23(38)$ & $20(24)$ & Reference & & & \\
\hline Yes, placebo & $19(31)$ & $29(35)$ & $0.55(0.24-1.28)$ & 0.17 & & \\
\hline Yes, nifedipine & $19(31)$ & $34(41)$ & $0.48(0.21-1.11)$ & 0.085 & & \\
\hline
\end{tabular}

Abbreviation: PPROM, premature prelabor rupture of membranes.

${ }^{a}$ Averaged over the 10 imputation sets using Rubin rules. Intercept -1.0760 . c-statistic $0.68(0.60-0.77)$. Coefficients were shrunken with an average shrinkage factor 0.72 .

${ }^{b}$ Data are mean \pm standard deviation, median (IQR) or number (\%). Percentages may not sum to 100 because of rounding. Absolute numbers are based on the mean of 10 imputations.

$p=1 /[1+\exp (-1 \times-3.8334+1.43 \times$ blood loss $+0.063 \times$ log.age $+1.83 \times$ fFN pos $+-0.68 \times$ cervical length)] for women without PPROM; and

$p=1 /[1+\exp (-1 \times-1.076+0.57 \times$ blood loss $+1.02 \times$ nulliparity $+-0.015 \times$ prior preterm birth $<32$ weeks $+0.99 \times$ prior preterm birth $32-37$ weeks)] for women with PPROM.

Most studies have concentrated on screening early in pregnancy and on the outcome of preterm delivery $<32$ to 37 weeks. ${ }^{26-30}$ Identifying patients at risk of preterm delivery should be considered differently at each stage of pregnancy. For example, early in pregnancy history of preterm birth and ethnicity are indicators for preterm delivery. ${ }^{26,28}$ In midpregnancy, fFN detection and cervical length are associated with preterm delivery. ${ }^{27,29,30}$ In symptomatic patients, fFN and cervical length improved identification of women with a low risk to deliver spontaneously within 7 days. ${ }^{31}$ In general, sensitivity and speci- ficity of these predictive factors are fairly low. We concentrated on women who did not deliver after initial therapy for threatened preterm labor because it may affect their management with regard to prolonged admission or discharge after initial medical treatment.

Several methodological aspects of the study deserve consideration: study population, missing values, unexpected results, over-, and underestimation.

We included both randomized and nonrandomized women in the study. Although this might raise concern about heterogeneity, we aimed to perform an analysis for all patients with arrested preterm labor-whether they participate in a randomized trial or not-to exclude the Hawthorn effect from these results. ${ }^{32}$ We feel we could do this because the intervention of maintenance tocolysis was not effective in prolonging pregnancy and improving perinatal outcome in the original trial.

We performed our study in all 10 Dutch tertiary care centers, which indicates good representation for the Dutch 
Table 3 Univariable and multivariable analyses for the prediction of delivery within 7 days after successful 48 hours treatment of threatened preterm labor in women without PPROM

\begin{tabular}{|c|c|c|c|c|c|c|}
\hline \multirow{2}{*}{$\begin{array}{l}\text { Women } \\
\text { without PPROM } \\
(n=484,77 \%)\end{array}$} & \multirow{2}{*}{$\begin{array}{l}\text { Delivery } \\
<7 \text { days }\end{array}$} & \multirow{2}{*}{$\begin{array}{l}\text { Delivery } \\
>7 \text { days }\end{array}$} & \multicolumn{2}{|l|}{ Univariable analysis } & \multicolumn{2}{|c|}{ Multivariable analysis } \\
\hline & & & $\begin{array}{l}\text { Odds ratio } \\
(95 \% \mathrm{CI})^{\mathrm{a}}\end{array}$ & $p$-Value & $\begin{array}{l}\text { Beta } \\
\text { coefficient }\end{array}$ & $\begin{array}{l}\text { Odds ratio } \\
\text { (95\% Cl) }\end{array}$ \\
\hline Characteristic & $n=90(19 \%)$ & $n=394(81 \%)$ & & & & \\
\hline Age $(y)^{b}$ & $30.9 \pm 4.6$ & $29.0 \pm 5.4$ & $0.72(0.46-1.12)^{c}$ & 0.14 & 0.063 & $1.07(1.00-1.13)$ \\
\hline $\begin{array}{l}\text { Non-Caucasian } \\
\text { ethnicity }\end{array}$ & $15(17)$ & $68(17)$ & $0.95(0.51-1.79)$ & 0.88 & & \\
\hline Low educational level & $45(50)$ & $237(60)$ & $0.68(0.40-1.16)$ & 0.15 & & \\
\hline \multicolumn{7}{|c|}{ Parity and prior preterm birth } \\
\hline Prior birth $\geq 37$ wk & $18(20)$ & $87(22)$ & Reference & & & \\
\hline Nulliparous & $59(65)$ & $219(56)$ & $1.29(0.72-2.32)$ & 0.39 & & \\
\hline $\begin{array}{l}\text { Prior preterm } \\
\text { birth }<32 \mathrm{wk}\end{array}$ & $7(8)$ & $54(14)$ & $0.63(0.25-1.60)$ & 0.33 & & \\
\hline $\begin{array}{l}\text { Prior preterm } \\
\text { birth } 32-37 \mathrm{wk}\end{array}$ & $6(7)$ & $34(9)$ & $0.85(0.31-2.33)$ & 0.76 & & \\
\hline $\begin{array}{l}\text { Body mass } \\
\text { index }\left(\mathrm{kg} / \mathrm{m}^{2}\right)\end{array}$ & $21.6(20.2-24.4)$ & $22.3(20.4-24.8)$ & $0.96(0.90-1.03)$ & 0.29 & & \\
\hline Multifetal gestation & $21(23)$ & $86(22)$ & $1.07(0.62-1.85)$ & 0.82 & & \\
\hline Vaginal bleeding & $36(40)$ & $50(13)$ & $4.64(2.77-7.79)$ & $<0.001$ & 1.43 & $4.20(2.07-8.52)$ \\
\hline $\begin{array}{l}\text { C-reactive } \\
\text { protein }(\mathrm{g} / \mathrm{L})\end{array}$ & $10(4-25)$ & $7(3-21)$ & $1.14(0.86-1.51)^{c}$ & 0.16 & & \\
\hline $\begin{array}{l}\text { Streptococcus } \\
\text { Group B positive }\end{array}$ & $23(25)$ & $81(21)$ & $1.31(0.72-2.41)$ & 0.38 & & \\
\hline $\begin{array}{l}\text { Fibronectin } \\
\text { status positive }\end{array}$ & $59(66)$ & $130(33)$ & $14.9(5.08-43.7)$ & $<0.001$ & 1.83 & $6.23(2.15-18.0)$ \\
\hline Dilatation $(\mathrm{cm})$ & $2(1-3)$ & $1(0-1)$ & $1.93(1.52-2.44)$ & $<0.001$ & & \\
\hline Cervical length (mm) & $12(7-18)$ & $24(16-32)$ & $0.36(0.25-0.52)$ & $<0.001$ & -0.68 & $0.50(0.34-0.75)$ \\
\hline \multicolumn{7}{|l|}{ Randomized } \\
\hline No & $24(27)$ & $155(39)$ & Reference & & & \\
\hline Yes, placebo & $37(41)$ & $120(30)$ & $1.99(1.13-3.51)$ & 0.02 & & \\
\hline Yes, nifedipine & $29(32)$ & $119(30)$ & $1.55(0.86-2.81)$ & 0.15 & & \\
\hline
\end{tabular}

Abbreviation: PPROM, premature prelabor rupture of membranes.

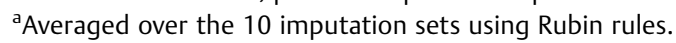

${ }^{b}$ Data are mean \pm standard deviation, median (IQR) or number (\%). Percentages may not sum to 100 because of rounding. Absolute numbers are based on the mean of 10 imputations.

${ }^{c}$ Log transformed. Intercept - 3.8334. c-statistic 0.89 (0.84-0.93). Coefficients were shrunken with an average shrinkage factor 0.92 .

population. From the population, $4.3 \%$ was of African ethnicity, and $14.7 \%$ was non-Caucasian non-African. African ethnicity is a well-known risk factor for preterm delivery, ${ }^{26,33}$ which we did not identify in our study. This is probably attributed to the fact that the incidence of African ethnicity in the study was low.

We did not include smoking in our analyses because smoking as a risk factor for preterm birth in the literature mostly included both spontaneous and medically indicated preterm births combined, ${ }^{34-36}$ and we feel that delivery within 7 days after arrest of threatened preterm labor is mostly based on only spontaneous preterm births.
We encountered missing values, for example, in fFN testing $60 \%$ of the values were missing. fFN testing was not standard in the Netherlands at the time of this trial, and women had to give separate informed consent for performing this test. To prevent loss in statistical power, we imputed missing values, which is superior to complete case analysis. ${ }^{19}$

We expected women with a prior preterm birth to have an increased risk of delivery within 7 days after arrest of threatened preterm labor in the current pregnancy in women without PPROM. ${ }^{28}$ We observed that this was not the case in our study. The unexpected finding may have been caused by intervention effects or selection bias. ${ }^{37}$ As 

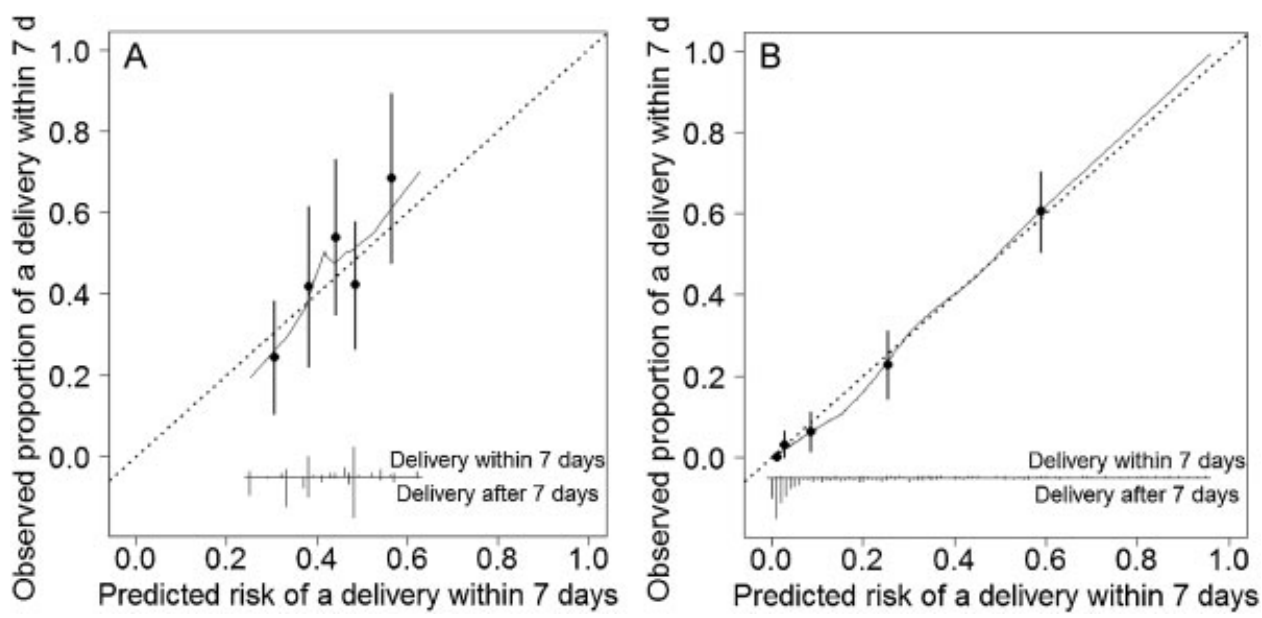

Fig. 2 (a) Calibration plot of model 1 (women with PPROM) with the observed risk of delivery within 7 days by predicted probabilities of delivery within 7 days. The dots indicate the deciles with $95 \%$ confidence intervals of women with similar predicted risk. The histograms indicate the frequencies across the predicted probabilities. (b) Calibration plot of model 2 (women without PPROM) with the observed risk of delivery within 7 days by predicted probabilities of delivery within 7 days. The dots indicate the deciles with $95 \%$ confidence intervals of women with similar predicted risk. The histograms indicate the frequencies across the predicted probabilities.

women with a prior preterm delivery may be treated earlier in the process of threatened preterm labor than women without a prior preterm delivery, it is possible that this led to a seemingly more effective treatment of threatened preterm labor, by starting treatment in the latent phase of labor instead of the acceleration phase of labor. Also, these women have more risk to delivery early, for example, in the first 48 hours after admission for threatened preterm labor. In that case, they were not even included in our trial. We cannot exclude the possibility of selection bias because collection of data on women who refuse randomization and refuse follow-up of their data (nonparticipants) is not allowed.

We observed slight over- and underestimation of risk for delivery within 1 week, as shown in - Fig. 2a, b. For the sum of variables, there is a tendency for slight overestimation of low predicted risk and for slight underestimation of high predicted risk (-Fig. 2a, b). The switch from overestimation in low predicted risk to underestimation in high predicted risk was at approximately $50 \%$ for women with PPROM and approximately $20 \%$ for women without PPROM. This is due to the low number of cases in the higher risk group of women without PPROM, which suggests that PPROM is a major risk factor for delivery within 1 week.

Women with initial arrest of threatened preterm labor remain at risk for delivery within 7 days. PPROM and vaginal bleeding in the current pregnancy are relevant predictive factors in all women, as are maternal age, cervical length, and fFN in women without PPROM and nulliparity, prior preterm birth $<32$ weeks, and prior preterm birth 32 to 37 weeks in women with PPROM. Most risk factors for delivery within 1 week after arrest of preterm labor are nonadjustable, for example, maternal age and history of preterm birth. Even so, it is of clinical use to know whether a woman is at high or low risk of delivery within 1 week, to determine the necessary level of care. Although women at low risk can be observed in secondary care or home care, women with a high risk may benefit from prolonged admission in a tertiary center.

\section{Authors' Contributions}

J.A.M.P., F.K.L., and B.W.J.M. contributed to the design of the randomized trial. All authors participated in recruitment of participants, and collected data. C.R. and E.S. analyzed and interpreted the data. C.R. drafted the article. All authors critically reviewed the report. All authors have seen and approved the final version.

\section{Funding Source}

The randomized trial was funded by ZonMw, the Netherlands Organization for Health Research and Development healthcare efficiency program (grant number $80-$ 82310-98-08210). The funder had no role in study design; collection, analysis, and interpretation of data; writing the report; or the decision to submit for publication.

\section{Conflict of Interest}

None.

\section{Ethical Approval}

The randomized trial was approved by the Academic Medical Center Institutional Review Board (MEC 07/ 286). Written informed consent was obtained from all participants before enrolment.

\section{Note}

The trial was registered in the Dutch Trial Register, NTR 1336, www.trialregister.nl. 


\section{Acknowledgment}

We thank research nurses, midwives, and secretaries of our consortium, and the residents, nurses, and gynecologists of the participating centers, for their help with participant recruitment and data collection.

\section{References}

1 Ananth CV, Vintzileos AM. Epidemiology of preterm birth and its clinical subtypes. J Matern Fetal Neonatal Med 2006;19(12):773-782

2 Goldenberg RL, Culhane JF, Iams JD, Romero R. Epidemiology and causes of preterm birth. Lancet 2008;371(9606):75-84

3 Papatsonis DN, Van Geijn HP, Adèr HJ, Lange FM, Bleker OP, Dekker GA. Nifedipine and ritodrine in the management of preterm labor: a randomized multicenter trial. Obstet Gynecol 1997;90(2):230-234

4 Goepfert AR, Goldenberg RL, Mercer B, et al; The National Institute of Child Health and Human Development Maternal-Fetal Medicine Units Network. The preterm prediction study: quantitative fetal fibronectin values and the prediction of spontaneous preterm birth. Am J Obstet Gynecol 2000;183(6):1480-1483

5 Iams JD, Goldsmith LT, Weiss G. The preterm prediction study: maternal serum relaxin, sonographic cervical length, and spontaneous preterm birth in twins. J Soc Gynecol Investig 2001;8(1):39-42

6 Kollée LA, Brand R, Schreuder AM, Ens-Dokkum MH, Veen S, Verloove-Vanhorick SP. Five-year outcome of preterm and very low birth weight infants: a comparison between maternal and neonatal transport. Obstet Gynecol 1992;80(4):635-638

7 Gotsch F, Gotsch F, Romero R, et al. The preterm parturition syndrome and its implications for understanding the biology, risk assessment, diagnosis, treatment and prevention of preterm birth. J Matern Fetal Neonatal Med 2009;22(Suppl 2):5-23

8 Roos C, Scheepers LH, Bloemenkamp KW, et al. Assessment of perinatal outcome after sustained tocolysis in early labour (APOSTEL-II trial). BMC Pregnancy Childbirth 2009;9:42

9 Roos C, Spaanderman ME, Schuit E, et al; APOSTEL-II Study Group. Effect of maintenance tocolysis with nifedipine in threatened preterm labor on perinatal outcomes: a randomized controlled trial. JAMA 2013;309(1):41-47

10 Goldenberg RL, Iams JD, Das A, et al; National Institute of Child Health and Human Development Maternal-Fetal Medicine Units Network. The Preterm Prediction Study: sequential cervical length and fetal fibronectin testing for the prediction of spontaneous preterm birth. Am J Obstet Gynecol 2000;182(3): 636-643

11 Meis PJ, Michielutte R, Peters TJ, et al. Factors associated with preterm birth in Cardiff, Wales. I. Univariable and multivariable analysis. Am J Obstet Gynecol 1995;173(2):590-596

12 Sanchez-Ramos L, Delke I, Zamora J, Kaunitz AM. Fetal fibronectin as a short-term predictor of preterm birth in symptomatic patients: a meta-analysis. Obstet Gynecol 2009;114(3):631-640

13 Sotiriadis A, Papatheodorou S, Kavvadias A, Makrydimas G. Transvaginal cervical length measurement for prediction of preterm birth in women with threatened preterm labor: a meta-analysis. Ultrasound Obstet Gynecol 2010;35(1):54-64

14 Sun GW, Shook TL, Kay GL. Inappropriate use of bivariable analysis to screen risk factors for use in multivariable analysis. J Clin Epidemiol 1996;49(8):907-916

15 Peduzzi P, Concato J, Kemper E, Holford TR, Feinstein AR. A simulation study of the number of events per variable in logistic regression analysis. J Clin Epidemiol 1996;49(12):1373-1379

16 Harrell FE Jr, Lee KL, Mark DB. Multivariable prognostic models: issues in developing models, evaluating assumptions and adequacy, and measuring and reducing errors. Stat Med 1996;15(4):361-387

17 Donders AR, van der Heijden GJ, Stijnen T, Moons KG. Review: a gentle introduction to imputation of missing values. J Clin Epidemiol 2006;59(10):1087-1091
18 Greenland S, Finkle WD. A critical look at methods for handling missing covariates in epidemiologic regression analyses. Am J Epidemiol 1995;142(12):1255-1264

19 van der Heijden GJ, Donders AR, Stijnen T, Moons KG. Imputation of missing values is superior to complete case analysis and the missing-indicator method in multivariable diagnostic research: a clinical example. J Clin Epidemiol 2006;59(10):1102-1109

20 Royston P, Moons KG, Altman DG, Vergouwe Y. Prognosis and prognostic research: Developing a prognostic model. BMJ 2009; 338:b604

21 Vergouwe Y, Royston P, Moons KG, Altman DG. Development and validation of a prediction model with missing predictor data: a practical approach. J Clin Epidemiol 2010;63(2):205-214

22 Rubin DB, Schenker N. Multiple imputation in health-care databases: an overview and some applications. Stat Med 1991;10(4):585-598

23 Steyerberg EW, Borsboom GJ, van Houwelingen HC, Eijkemans MJ, Habbema JD. Validation and updating of predictive logistic regression models: a study on sample size and shrinkage. Stat Med 2004; 23(16):2567-2586

24 Steyerberg EW, Bleeker SE, Moll HA, Grobbee DE, Moons KG. Internal and external validation of predictive models: a simulation study of bias and precision in small samples. J Clin Epidemiol 2003; 56(5):441-447

25 Miller ME, Hui SL, Tierney WM. Validation techniques for logistic regression models. Stat Med 1991;10(8):1213-1226

26 Culhane JF, Goldenberg RL. Racial disparities in preterm birth. Semin Perinatol 2011;35(4):234-239

27 Goldenberg RL, Iams JD, Mercer BM, et al; National Institute of Child Health and Human Development Maternal-Fetal Medicine Units Network. What we have learned about the predictors of preterm birth. Semin Perinatol 2003;27(3):185-193

28 Iams JD, Goldenberg RL, Mercer BM, et al; National Institute of Child Health and Human Development Maternal-Fetal Medicine Units Network. The Preterm Prediction Study: recurrence risk of spontaneous preterm birth. Am J Obstet Gynecol 1998;178(5): 1035-1040

29 Iams JD, Goldenberg RL, Mercer BM, et al; National Institute of Child Health and Human Development Maternal-Fetal Medicine Units Network. The preterm prediction study: can low-risk women destined for spontaneous preterm birth be identified? Am J Obstet Gynecol 2001;184(4):652-655

30 Sananès N, Langer B, Gaudineau A, et al. Prediction of spontaneous preterm delivery in singleton pregnancies: where are we and where are we going? A review of literature. J Obstet Gynaecol 2014;34(6):457-461

31 van Baaren GJ, Vis JY, Wilms FF, et al. Predictive value of cervical length measurement and fibronectin testing in threatened preterm labor. Obstet Gynecol 2014;123(6):1185-1192

32 McCambridge J, Witton J, Elbourne DR. Systematic review of the Hawthorne effect: new concepts are needed to study research participation effects. J Clin Epidemiol 2014;67(3):267-277

33 MacDorman MF. Race and ethnic disparities in fetal mortality, preterm birth, and infant mortality in the United States: an overview. Semin Perinatol 2011;35(4):200-208

34 Burguet A, Kaminski M, Abraham-Lerat L, et al; EPIPAGE Study Group. The complex relationship between smoking in pregnancy and very preterm delivery. Results of the Epipage study. BJOG 2004;111(3):258-265

35 Jaddoe VW, Troe EJ, Hofman A, et al. Active and passive maternal smoking during pregnancy and the risks of low birthweight and preterm birth: the Generation R Study. Paediatr Perinat Epidemiol 2008;22(2):162-171

36 Savitz DA, Dole N, Herring AH, et al. Should spontaneous and medically indicated preterm births be separated for studying aetiology? Paediatr Perinat Epidemiol 2005;19(2):97-105

37 Schuit E, Groenwold RH, Harrell FE Jr, et al. Unexpected predictoroutcome associations in clinical prediction research: causes and solutions. CMAJ 2013;185(10):E499-E505 


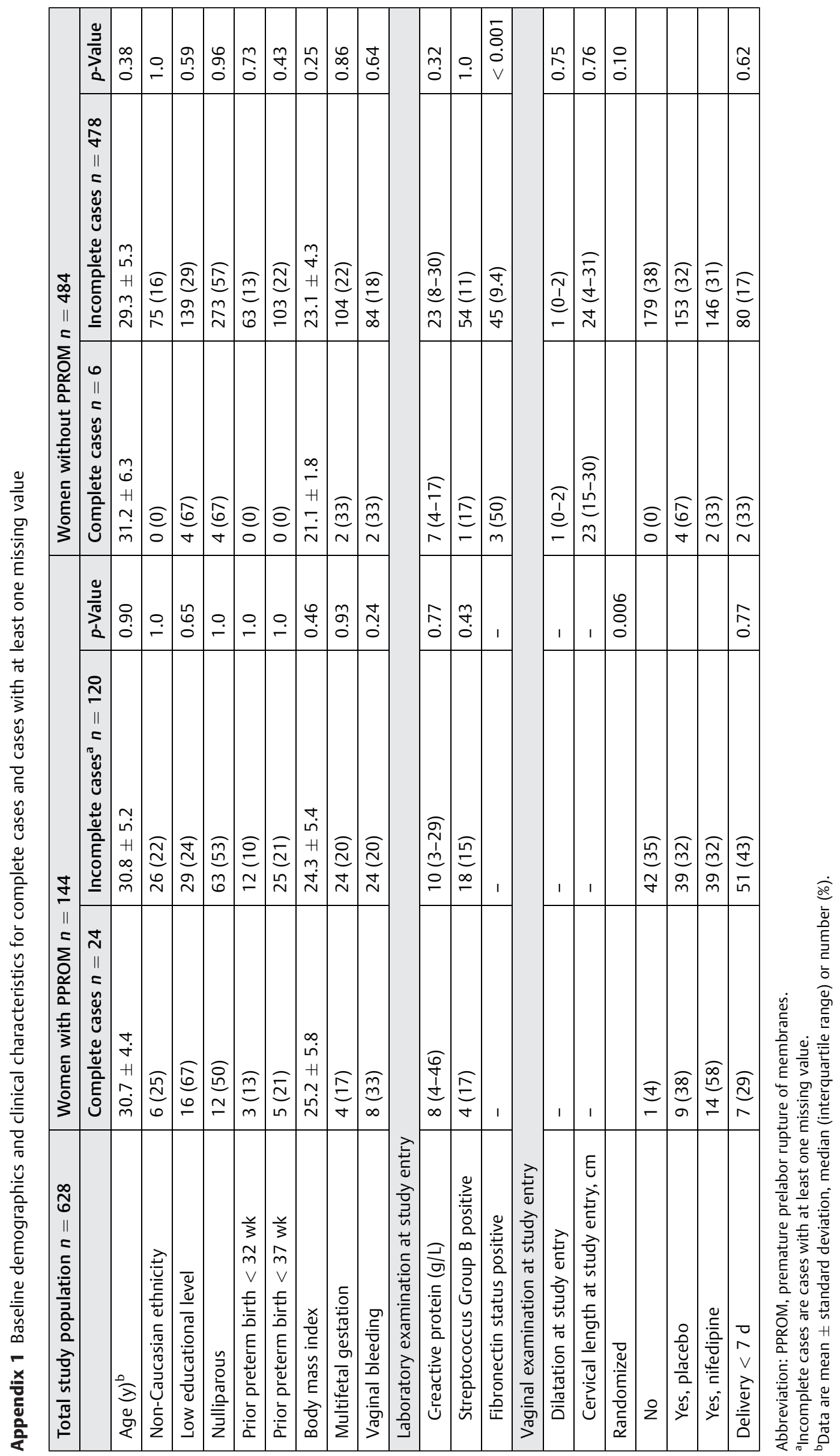

